\title{
Absorption of 'fortification' iron
}

\author{
Bioavailability in man of different samples of reduced $\mathrm{Fe}$, and \\ prediction of the effects of Fe fortification
}

\author{
BY E. BJÖRN-RASMUSSEN, L. HALLBERG AND L. ROSSANDER \\ Department of Medicine II, Sahlgrenska Sjukhuset, S-4I3 45 Göteborg, Sweden
}

(Received 26 May 1976-Accepted 4 October 1976)

\begin{abstract}
I. The first part of this study was designed to determine the increase in the amount of iron absorbed by hypothetical groups of subjects on the border-line of Fe deficiency when they were given meals fortified with ferrous sulphate. Two levels of $\mathrm{Fe}$ fortification were used ( .6 and $8.9 \mathrm{mg} / \mathrm{meal}$ ) and the increase in the amount of $\mathrm{Fe}$ absorbed by the 'border-line' groups was 0.13 and $0.7 \mathrm{mg}$ respectively.

2. Subjects which are on the border-line of Fe deficiency may be considered the target group of an Fe-fortification programme. Therefore the experimental model used can provide valuable information on the effects on the prevalence of $\mathrm{Fe}$ deficiency which can be expected when such a programme is introduced.

3. In the second part of the study, the bioavailability in man of reduced Fe with different physico-chemical properties was measured. Special emphasis was given to the relationship between the values obtained in vitro and in vivo.

4. The bioavailability was expressed as absorbability relative to that of ferrous sulphate. In four samples of hydrogen-reduced $F e$ the bioavailability ranged from 90 to $13 \%$. The reduced-Fe products differed considerably with respect to solubility in hydrochloric acid $(8-94 \%$ dissolved after $30 \mathrm{~min})$, particle size distribution $(9 \mathrm{I}-\mathrm{r} \%<7 \mu \mathrm{m})$ and reactive surface area $\left(<0 \cdot 1-2 \cdot 7 \mathrm{~m}^{2} / \mathrm{g}\right)$.

5. The relationships found between physico-chemical information and bioavailability indicated that reactive surface area and dissolution rate were better predictors of the bioavailability than the particle size.
\end{abstract}

Fortification of foods with iron is currently used, or planned to be introduced, in many countries in order to reduce the high prevalence of Fe deficiency. Very little is known, however, about the amount of Fe which is absorbed, and the effects on the prevalence of $\mathrm{Fe}$ deficiency which can be expected when the $\mathrm{Fe}$ content of a diet is increased by fortification of, for example, cereal foods. The reason is that no method has been available to measure absorption of Fe from composite meals.

The purpose of $\mathrm{Fe}$ fortification is not primarily to treat but to prevent $\mathrm{Fe}$ deficiency. $A$ long period of observation is therefore needed to be able to detect a decrease in the prevalence of $\mathrm{Fe}$ deficiency in a population after the introduction of $\mathrm{Fe}$ fortification of the diet or the improvement of an existing programme. Moreover, the cause of a change in the Fe status of a population may be difficult to establish as many factors may be involved, including altered food habits, the use of oral contraceptives or intra-uterine devices, and Fe prophylaxis to pregnant women.

The recently developed extrinsic-tracer method has made it possible to carry out valid measurements of the absorption of Fe from composite meals (Cook, Layrisse, Martinez-Torres, Walker, Monsen \& Finch, 1972; Hallberg \& Björn-Rasmussen, 1972; Layrisse \& Martinez-Torres, 1972). This new method is based on findings 
which indicate that there is an almost complete and rapid isotopic exchange between naturally-occurring non-haem-Fe in the food, and added extrinsic inorganic radio- $\mathrm{Fe}$ tracer. This isotopic exchange is considered to take place in a common pool of nonhaem-Fe formed by the different kinds of non-haem-Fe in a meal (Björn-Rasmussen, Hallberg \& Walker, 1972; Björn-Rasmussen, 1973c). One implication of the pool concept is that $\mathrm{Fe}$ added as fortification to certain foods in a meal will enter the nonhaem-Fe pool. The only provisions are that the 'fortification' $\mathrm{Fe}$ is a non-haem-Fe compound and that it can be dissolved under the conditions prevailing in the gastrointestinal tract (Björn-Rasmussen, $1973 b$ ). Another important implication of the pool concept is that factors in the diet (e.g. foods, additives, drinks) which influence the absorbability of intrinsic hon-haem-Fe from a meal will affect similarly the absorption of both the intrinsic non-haem-Fe and the added Fe (Björn-Rasmussen, r973a, $c$; Layrisse, Martinez-Torres, Cook, Walker \& Finch, 1973).

The absorption of 'fortification' Fe from a meal is affected by several factors, such as the composition of the meal, the amount of $\mathrm{Fe}$ present in the meal, the bioavailability of the Fe compounds used for fortification, and the Fe status of the subjects studied. Therefore, in order to be able to predict the effects of a fortification programme, knowledge is needed about all these factors as well as about the variation in the $\mathrm{Fe}$ requirements of the population.

The present paper describes studies on some of these factors. One part of the study was devoted to studies on the relationship between the level of fortification and absorption and the influence of the Fe status of the subjects. Another part of the study was devoted to determination of the bioavailability in man of reduced Fe with different physico-chemical properties. Special emphasis was given to the relationship between the values obtained in vitro and in vivo.

EX PER I MENTAL

\section{Fe compounds studied}

Six commercially available samples of reduced $\mathrm{Fe}$ (samples A-G) were studied more or less extensively. Samples A-D were prepared by electrolysis and sample F by the carbonyl process. The manufacturing process of sample $\mathrm{G}$ was unknown.

All the variants of sample $\mathrm{E}$ were made by a Swedish chemical manufacturer (Elektrokemiska AB, S-445 or Surte, Sweden) in close collaboration with our laboratory. They were prepared by hydrogen reduction and were made especially for the present study. A variant of this sample of reduced $\mathrm{Fe}$ is in the process of being introduced commercially. Most of the variants were not labelled with radio-Fe (samples EI-6). Four samples were labelled with radio-Fe (samples EII-14). These samples were used in absorption studies designed to establish the relationship between bioavailability and dissolution rate.

To ensure homogeneous labelling the tracer was added to the Fe compound before H-reduction. By modifications of the manufacturing process, it was possible to prepare radio-Fe-labelled, reduced Fe with different solubility properties. Four such samples were made and used for studies on bioavailability and on dissolution rate. 
The reactive surface area of these labelled compounds was not measured because fairly large amounts were needed for the method used.

\section{Effect of storage}

Four samples of reduced $\mathrm{Fe}$ (samples $\mathrm{C}, \mathrm{E} 2, \mathrm{~F}$ and $\mathrm{G}$ ) were kept exposed to air at two temperatures and two relative humidities. There were no differences in dissolution rates before and after storage for $I$ month.

\section{Determination of dissolution rate}

The dissolution rate of different $\mathrm{Fe}$ compounds was studied in hydrochloric acid at $\mathrm{pH}$. Weighed amounts of the compounds, corresponding to $16 \mathrm{mg}$ elemental $\mathrm{Fe}$ and $200 \mathrm{ml} \mathrm{O} \cdot \mathrm{I} \mathrm{M}-\mathrm{HCl}$ were shaken in a $500 \mathrm{ml}$ flask at $23^{\circ}$ using horizontal agitation (amplitude $60 \mathrm{~mm}$, frequency 130 cycles/min). Duplicate I $\mathrm{ml}$ samples were withdrawn at various intervals during the first $30 \mathrm{~min}$ after the start of the agitation. The samples were immediately filtered through an acid-washed, fine-pore filter-paper and the $\mathrm{Fe}$ content of the filtrate was determined (International Committee for Standardization in Hematology, 1971). Each solubility study was done in duplicate.

The reproducibility of the method used to measure the dissolution rate was determined for both a readily-soluble compound (sample $E_{3}$ ) and a less-readilysoluble compound (sample D). Six determinations were made on each compound. The mean amount $( \pm \mathrm{SD})$ of $\mathrm{Fe}$ dissolved at 30 min was $81 \pm 3 \%$ for sample $E_{3}$ and $58 \pm 2 \cdot 4 \%$ for sample D. Thus the coefficient of variation at 3 o min was $3 \cdot 7$ for sample $E_{3}$ and $4 \cdot I$ for sample $D$.

\section{Determination of particle size distribution and surface area}

A suspension of the Fe powder in glycerol was analysed using a light microscope with a measuring ocular. Magnifications of $\times 100-\times 400$ were used. A more dilute sample was prepared if the particles were not evenly dispersed and thus touching each other. The lengths of at least 200 particles were measured.

Determination of the reactive surface area was made using the 'BET' method (Brunauer, Emmett \& Teller, 1938).

\section{Absorption studies}

Seventy-one male and female subjects aged between 18 and 50 years volunteered for the absorption studies. They all considered themselves healthy and they had no history of anaemia or gastrointestinal disease. The absorption studies were done in the morning in the laboratory, the subjects having fasted overnight. After ingestion of the test meal or test solutions no food or drink was allowed for $3 \mathrm{~h}$. Before the absorption study, blood samples were taken for determination of haemoglobin, packed cell volume, plasma $\mathrm{Fe}$ concentration (International Committee for Standardization in Hematology, 1971), and total Fe-binding capacity (Herbert, Gottlieb, Lau, Fisher, Gevirtz, \& Wasserman 1966). All individual values were within the normal range.

The absorption of non-haem-Fe from food was determined using the extrinsic- 
tracer method (Hallberg \& Björn-Rasmussen, I 972). Two isotopes were used, ${ }^{55} \mathrm{Fe}$ and ${ }^{59} \mathrm{Fe}$. The absorption of the tracers was determined by the simultaneous use of a sensitive $3 \pi$ whole-body counter (Arvidsson, Sköldborn \& Isaksson, I972; Sköldborn, Arvidsson \& Andersson, 1972) and radioactivity in blood samples was determined as previously described (Eakins \& Brown, I966; Björn-Rasmussen, Hallberg, Isaksson \& Arvidsson, 1974). Two series of studies were performed to determine first the effect of $\mathrm{Fe}$ fortification and second the bioavailability in man.

\section{Studies on the effect of Fe fortification}

This study was designed to estimate the increase in the amount of $\mathrm{Fe}$ absorbed when composite meals of 'lunch' or 'dinner' type were fortified with Fe. Unfortified meals and meals fortified with ferrous sulphate were served on different days to the same subjects, and the non-haem-Fe of the meals was labelled with two different isotopes. Two levels of Fe fortification were studied in two groups of subjects. The amount of $\mathrm{Fe}$ absorbed from reference doses of ferrous ascorbate was measured 2 weeks later as a basis for comparison of different subjects, and as a measure of the ability to absorb Fe (see p. 384).

Preparations of meals. The meals were composed of sixteen food items in which the relative amounts of the foodstuffs were similar to the average consumption at lunch or dinner in the Swedish population. The meals consisted of $(\mathrm{g})$ : milk products 134, vegetables and roots 82 , fruits and jam 55 , meat and fish 35 , cereals 22, egg 5 . All food components were carefully minced and mixed with an added inorganic radioFe tracer. The meals were weighed into aluminium dishes which were placed in a water-bath and then boiled for $2 \mathrm{~h}$ in an oven set at $200^{\circ}$. Some of the meals were fortified with $\mathrm{FeSO}_{4}$ which was added as a solution and thoroughly mixed into the food before cooking. The total non-haem-Fe content of the unfortified meals was $2.4 \mathrm{mg}$ and those of the two fortified meals were $4^{\circ} \mathrm{O}$ and $\mathrm{Ir}_{3} \cdot 3 \mathrm{mg}$, respectively. The unfortified meals were labelled with $4 \mu \mathrm{Ci}{ }^{55} \mathrm{FeCl}_{3}$ and the meals fortified with $\mathrm{FeSO}_{4}$ were labelled with $2 \mu \mathrm{Ci}{ }^{59} \mathrm{Fe}$.

The absorption of haem-Fe was not measured. Portions of the labelled meals were taken for analysis of ${ }^{55} \mathrm{Fe}$ and ${ }^{59} \mathrm{Fe}$. The $\mathrm{Fe}$ content of the meals was determined as previously described (Björn-Rasmussen et al. 1974). The reference doses contained $3 \mathrm{mg} \mathrm{Fe}$ as ferrous ascorbate and $30 \mathrm{mg}$ ascorbic acid in $10 \mathrm{ml} 0.1 \mathrm{M}-\mathrm{HCl}$.

Serving procedure. One group of nineteen subjects were served two unfortified meals (A) and two meals fortified to the level of $4.0 \mathrm{mg} \mathrm{Fe}(\mathrm{B})$. The meals were served in the order $A B B A$ or $B A A B$ on four consecutive mornings. The meals fortified to the higher level, II.3 $\mathrm{mg}(\mathrm{C})$, and the unfortified meals (A) were served, as described previously, to another group of eighteen subjects in the order ACCA or CAAC.

A blood sample was taken 2 weeks after the last serving for determination of ${ }^{55} \mathrm{Fe}$ and ${ }^{59} \mathrm{Fe}$, and the total retention of ${ }^{59} \mathrm{Fe}$ was measured by whole-body counting. Then, on two consecutive mornings, reference doses of $\mathrm{Fe}$ ascorbate were given. These doses were labelled with ${ }^{59} \mathrm{Fe}$. After a further 2 weeks the retention of the reference doses of Fe was measured by whole-body counting. 


\section{Bioavailability studies}

Four different variants of a sample of $\mathrm{H}$-reduced $\mathrm{Fe}$ (samples $\mathrm{E}_{\text {I I-I4) }}$ ) were studied. The reduced-Fe sample was labelled with ${ }^{55} \mathrm{Fe}$. The bioavailability was studied in wheat rolls fortified with the labelled, reduced-Fe samples. During preparation of the wheat rolls $0.5 \mathrm{mg}$ reduced $\mathrm{Fe}$, labelled with $3 \mu \mathrm{Ci}{ }^{55} \mathrm{Fe}$, was added to $30 \mathrm{~g} \mathrm{'} 60 \%$ extraction' wheat flour. At the same time, trace amounts of $\mathrm{FeCl}_{3}$ labelled with г $\mu \mathrm{Ci}{ }^{59} \mathrm{Fe}$ were also added. The baking procedure was the same as that described previously (Björn-Rasmussen et al. 1972). The total amount of $\mathrm{Fe}$ in each wheat roll was $2.2 \mathrm{mg}$, of this amount $0.5 \mathrm{mg} F$ was added reduced $\mathrm{Fe}$, and $\mathrm{I} \cdot 7 \mathrm{mg} \mathrm{Fe}$ was non-haem-Fe in the wheat flour.

Subjects in four groups were each served two wheat rolls, together with tap water. The wheat rolls served to each group contained one of the four labelled, reduced-Fe compounds (samples EII-I4).

The bioavailability of one of the Fe compounds (sample $E_{12}$ ) was also determined in another group of eight subjects using a different experimental design. To reduce the possibility of an isotopic exchange between the ${ }^{55} \mathrm{Fe}$-labelled, reduced $\mathrm{Fe}$ and the ${ }^{59} \mathrm{Fe}$-labelled $\mathrm{Fe}$ salt, the two different tracers were added to two separate batches of wheat rolls ( $A$ and $B$ respectively) which were served separately in the order $A B B A$ on four consecutive days. The two batches of wheat rolls, $A$ and $B$, were baked in the same way as the other wheat rolls used in this study, and were made to contain the same amount of elemental $\mathrm{Fe}(0.5 \mathrm{mg} /$ wheat roll).

\section{RESULTS}

\section{Solubility studies}

The dissolution rates of eight samples of reduced $\mathrm{Fe}$ at $\mathrm{pH}$ i and of the radio- $\mathrm{Fe}$ labelled samples of reduced Fe (samples EII-I4) are shown in Fig. I. The amount of Fe dissolved after 10, 20 and 30 min was also determined for samples $E_{I}-6$.

\section{Particle size and surface area}

The particle size distribution and the reactive surface area was determined for all the Fe compounds which were not labelled with radio-Fe. The results are given in Table I. The relationship between the amounts of Fe dissolved at intervals after the start of agitation and both the reactive surface area and the median particle size are shown in Fig. 2.

\section{Effect of fortification of a composite meal}

One group of nineteen subjects was served a 'lunch' meal on four consecutive mornings. Two of the meals were not fortified and contained $2.4 \mathrm{mg}$ non-haem-Fe/ meal. The other two meals were fortified with $\mathrm{FeSO}_{4}$ so that the total $\mathrm{Fe}$ content was $4.0 \mathrm{mg} / \mathrm{meal}$. The mean $( \pm \mathrm{SEM})$ amounts of Fe absorbed from the unfortified and fortified meals were $5 \cdot 6 \pm r^{\prime} I$ and $6 \cdot 5 \pm 1 \cdot 4 \%$ respectively. The difference in absorption was not significant but the amount of $\mathrm{Fe}$ absorbed increased significantly 


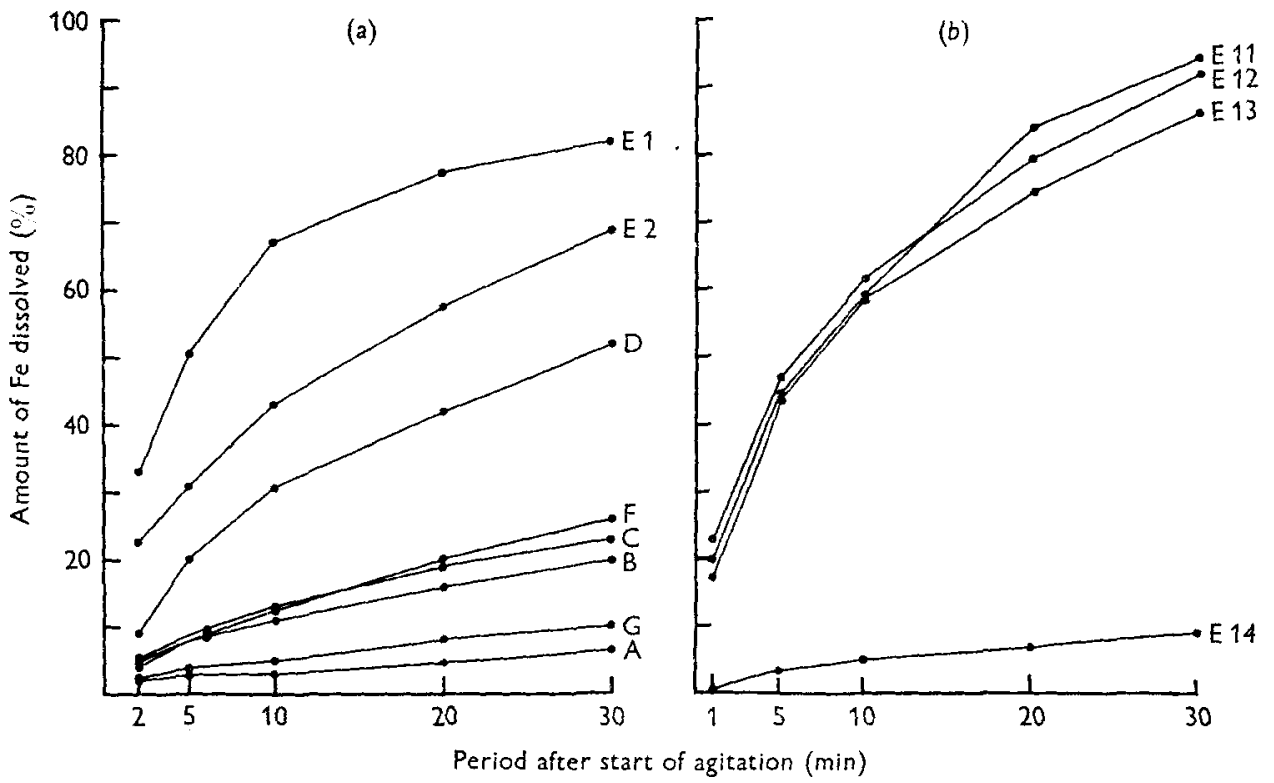

Fig. I. Dissolution rates (amount of iron dissolved in $0.1 \mathrm{M}$-hydrochloric acid (\%) at intervals after the start of agitation ( $\mathrm{min})$ ) of $(a)$ six different commercially available samples of reduced Fe (samples $A-G$ ) and two different samples of hydrogen-reduced $F e$ (samples $E_{1}$ and $E_{2}$ ) and $(b)$ four different samples of radio-Fe-labelled-reduced Fe (samples EII-14). For details of samples, see p. 376 and for details of experimental procedures, see p. 377 . Mean values for six determinations/sample.

Table I. Reactive surface area and median particle size for six different commercially available samples of reduced iron (samples $A-D, F$ and $G$ ) and of six different variants of hydrogen-reduced $\mathrm{Fe}$ (samples $E_{\mathrm{I}}-6$ )

\begin{tabular}{|c|c|c|c|c|c|c|c|c|c|c|}
\hline \multirow[b]{2}{*}{ Sample } & \multirow{2}{*}{$\begin{array}{l}\text { Reduction } \\
\text { process }\end{array}$} & \multirow[b]{2}{*}{ Shape } & \multirow{2}{*}{$\begin{array}{c}\text { surface } \\
\text { area } \\
\left(\mathrm{m}^{2} / \mathrm{g}\right)\end{array}$} & \multirow{2}{*}{$\begin{array}{l}\text { particle } \\
\text { size } \\
(\mu \mathrm{m})\end{array}$} & \multicolumn{6}{|c|}{ Particle size distribution $(\%)$} \\
\hline & & & & & $\leqslant 7 \mu \mathrm{m}$ & $14 \mu \mathrm{m}$ & $2 \mathrm{I} \mu \mathrm{m}$ & $28 \mu \mathrm{m}$ & $35 \mu \mathrm{m}$ & $>3 \mu \mathrm{m}$ \\
\hline A) & & & $<0.1$ & $35^{\circ} 0$ & $\mathbf{I}$ & 10 & 17 & 14 & 17 & $4 I$ \\
\hline B & Electrolytic & Irregular & $<0 \cdot 1$ & $42 \cdot 0$ & 4 & 23 & 9 & 6 & 7 & $5 I$ \\
\hline C & & & $<0.1$ & 3.4 & 72 & 7 & 7 & 2 & 3 & 9 \\
\hline D I & & & 0.40 & $5 \cdot 1$ & 69 & 20 & 7 & I & 2 & $I$ \\
\hline $\mathrm{EI}_{\mathrm{I}}$ & & & $\begin{array}{c}2.70 \\
1.81\end{array}$ & & & & & & & \\
\hline $\left.\begin{array}{l}\mathrm{E}_{3} \\
\mathrm{E}_{4} \\
\mathrm{E}_{5} \\
\mathrm{E}_{6}\end{array}\right\}$ & Hydrogen & Nodular & $\left.\begin{array}{l}2.00 \\
0.90 \\
0.97 \\
x .03\end{array}\right\}$ & $1 \cdot 7$ & $9 \mathrm{r}$ & 7 & $x$ & $\mathbf{I}$ & - & 一 \\
\hline $\mathbf{F}$ & Carbonyl & Spherical & 0.20 & 34 & 85 & 10 & 3 & 2 & - & - \\
\hline $\mathbf{G}$ & $\begin{array}{l}\text { Unknown } \\
\text { (probably } \\
\text { electrolytic) }\end{array}$ & Irregular & $<0.1$ & II $\cdot 9$ & 24 & 41 & 28 & 5 & 2 & - \\
\hline
\end{tabular}

- For details of samples, see p. 376 . 

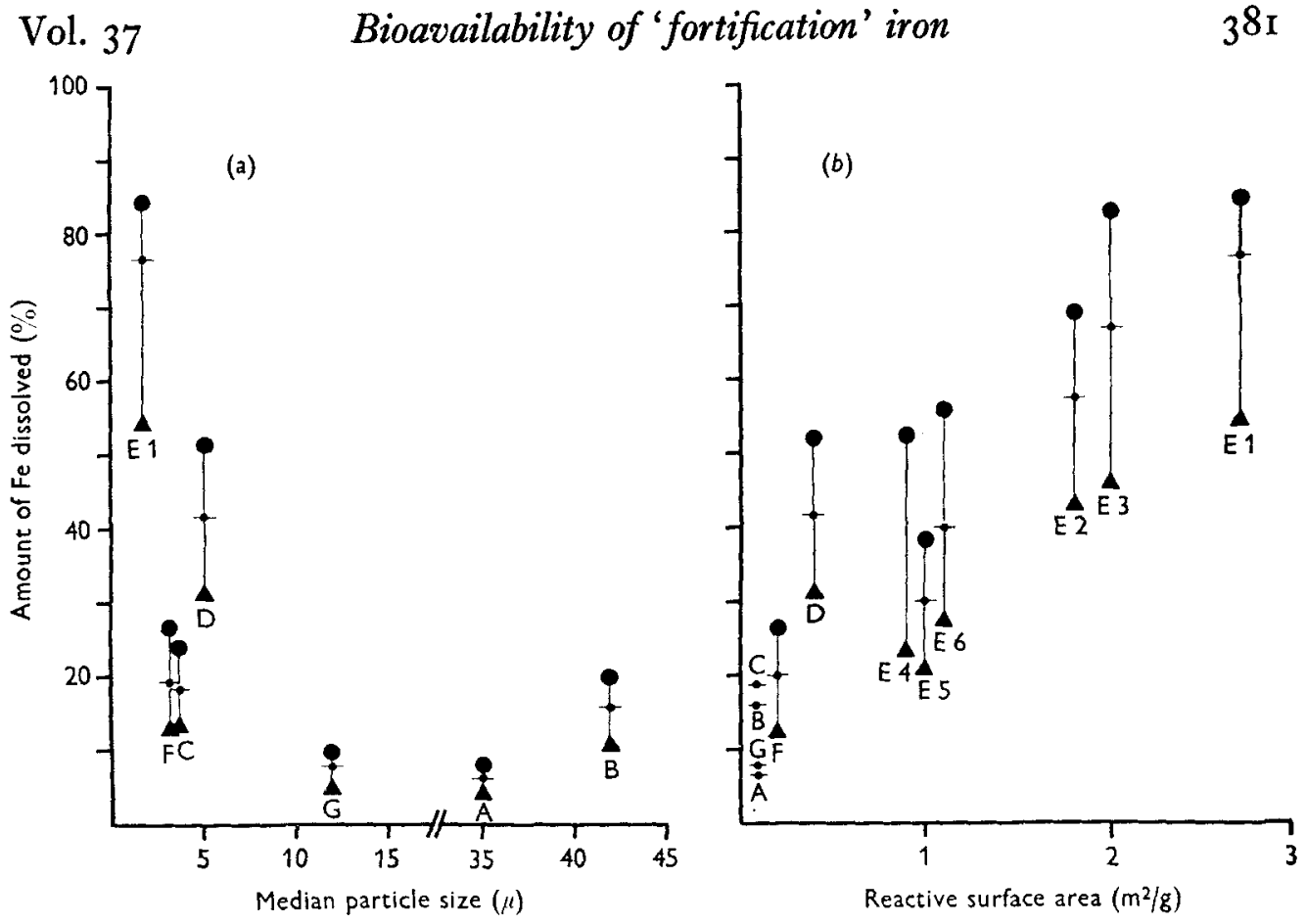

Fig. 2. The relationship between dissolution rates (amount of iron dissolved in $0.1 \mathrm{M}$ hydrochloric acid at $10(\Delta), 20(-)$ ) and $30(O)$ min intervals after the start of agitation) and $(a)$ the median particle size $(\mu)$, and $(b)$ the reactive surface area $\left(\mathrm{m}^{2} / \mathrm{g}\right)$ for six different commercially available samples of reduced Fe (samples $A-G$ ), and for six variants of one sample prepared by hydrogen reduction (samples $E_{I}-6$ ). For details of samples, see p. 376 and for details of experimental procedures, see p. 377 .

from 0.13 to $0.26 \mathrm{mg}$. The mean ( $\pm \mathrm{SEM}$ ) amount of Fe absorbed from the reference dose ( $3 \mathrm{mg} \mathrm{Fe}$ as ferrous ascorbate) was $3^{8 \cdot 5} \pm 4 \cdot 2 \%$ (Table 2 ).

Four 'lunch' meals were served on four consecutive mornings to another group of eighteen subjects. These meals were identical to the meals given to the previous group. Two of the meals were not fortified and the other two were fortified with $\mathrm{FeSO}_{4}$ so that the total Fe content was II. $3 \mathrm{mg} /$ meal. The mean ( $\pm \mathrm{SEM}$ ) amounts of Fe absorbed from the unfortified and fortified meals were $6.9 \pm I \cdot I$ and $7 \cdot 7 \pm I \cdot 4 \%$ respectively. The difference between the two mean absorption values was significant $(P<0.05$; paired $t$ test). The amount of $\mathrm{Fe}$ absorbed from the fortified meals was about five times higher than that absorbed from the unfortified meals, 0.87 and $0.17 \mathrm{mg}$ respectively $(P<0.0 \mathrm{I})$. The mean $( \pm \mathrm{SEM})$ amount of $\mathrm{Fe}$ absorbed from the reference dose was $36 \cdot 5 \pm 4 \cdot 4 \%$ (Table 2 ).

\section{Bioavailability of reduced $\mathrm{Fe}$}

Four groups of subjects were served wheat rolls baked from flour fortified with one of four different variants of a ${ }^{55} \mathrm{Fe}$-labelled, reduced Fe compound (samples EI I-I4). The same wheat rolls contained ${ }^{59} \mathrm{FeCl}_{3}$ added as an extrinsic tracer of the amount of Fe absorption from the non-haem-Fe pool.

The absorption of ${ }^{55} \mathrm{Fe}$ and ${ }^{59} \mathrm{Fe}$ tracers was compared in each subject. The values 
Table 2. Absorption in man of non-haem-iron from composite meals, ${ }^{*}$ unfortified (containing $2.4 \mathrm{mg} \mathrm{Fe}$ and labelled with ${ }^{55} \mathrm{Fe}$ ) $(A)$ or fortified with ferrous sulphate (containing $4^{\circ} \circ$ and $\mathrm{I} \cdot 3 \mathrm{mg} F e$ and labelled with $\left.{ }^{59} \mathrm{Fe}\right)\left(B \mathrm{I}\right.$ and $\mathrm{B}_{2}$ respectively) $\dagger$

(Mean values with their standard errors)

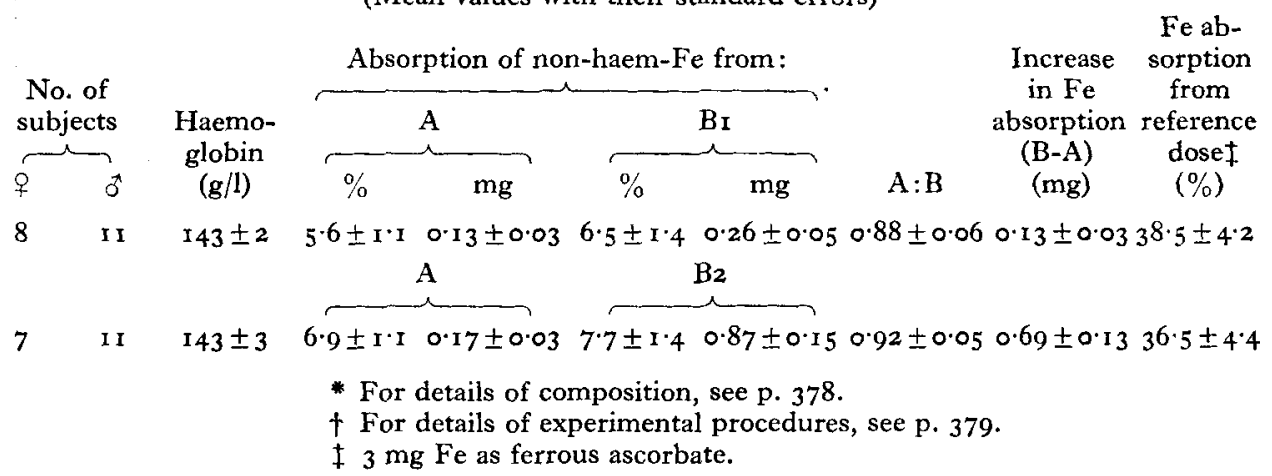

Table 3. Bioavailability in man of four variants of a sample of ${ }^{55} \mathrm{Fe}$-labelled, hydrogenreduced $\mathrm{Fe}$ when given together with ${ }^{59} \mathrm{FeCl}_{3}$ in two wheat rolls/subject served at one bread meal (I) and when the two isotopes were added to two separate batches of wheat rolls (A and B) and served at four bread meals on four consecutive days in the order ABBA (2)

(Mean values with their standard errors)

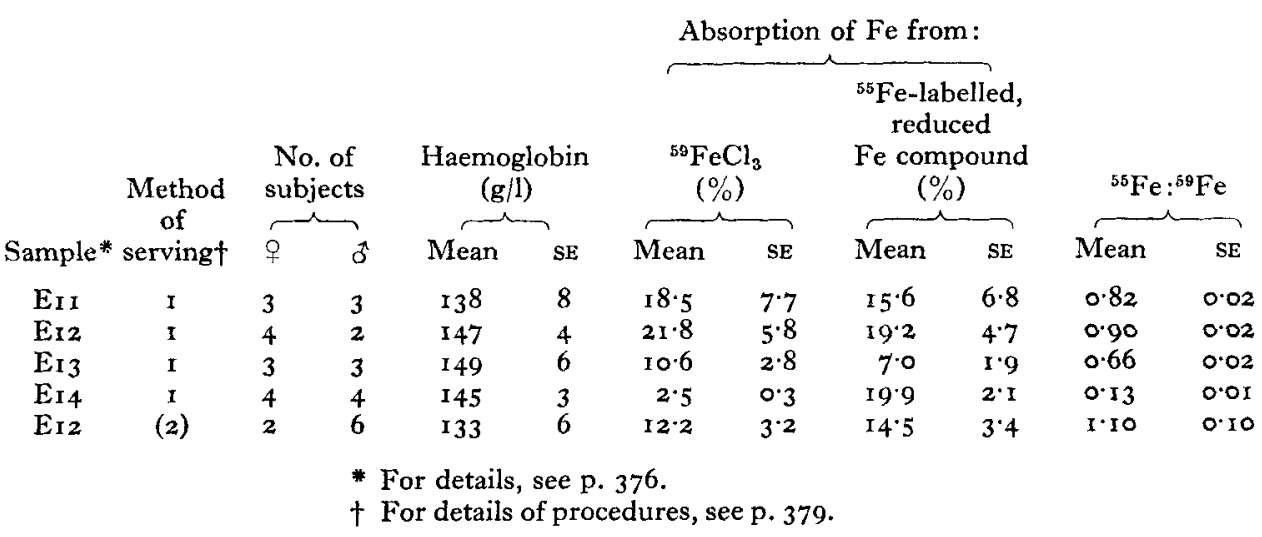

for the absorption of each tracer and the values for the absorption ratio, ${ }^{55} \mathrm{Fe}:{ }^{59} \mathrm{Fe}$, are given in Table 3 . The mean $( \pm \mathrm{SE})$ value for ${ }^{55} \mathrm{Fe}:{ }^{59} \mathrm{Fe}$ for the group receiving sample $E_{I I}$ was $0.82 \pm 0.02$ and the corresponding values for samples $E_{I_{2}}, E_{I_{3}}$ and $E_{I 4}$ were $0.90 \pm 0.02,0.66 \pm 0.02$ and $0.13 \pm 0.01$ respectively.

A fifth group of eight subjects was served four wheat rolls, one wheat roll/d on four consecutive days. Two of the wheat rolls each contained $0.5 \mathrm{mg}{ }^{55} \mathrm{Fe}$-labelled, reduced Fe powder (sample $\mathrm{E}_{12}$ ) and the other two each contained $0.5 \mathrm{mg} \mathrm{Fe}$ as ${ }^{59} \mathrm{FeSO}_{4}$. The mean $( \pm \mathrm{SE})$ amounts of the ${ }^{55} \mathrm{Fe}$ and ${ }^{59} \mathrm{Fe}$ tracers absorbed were $14.5 \pm 3.4$ and $12 \cdot 2 \pm 3 \cdot 2 \%$ respectively. The mean value for ${ }^{55} \mathrm{Fe}:{ }^{59} \mathrm{Fe}$ was $1 \cdot 10 \pm 0 \cdot 10$ (Table 3 ). 


\section{DISCUSSION}

\section{Effect of an Fe-fortification programme: methodological considerations}

In predicting the effects of an Fe-fortification programme several factors have to be considered, such as the bioavailability of the $\mathrm{Fe}$ compound used, the amount of $\mathrm{Fe}$ added, the composition of frequently consumed meals and the Fe status of the target population. A factorial experimental design is highly efficient in establishing the relative role of various factors involved. One factor known to influence $\mathrm{Fe}$ absorption markedly is the Fe status of the subjects. The usual haematological criteria are too poorly correlated with absorption to be of practical use. The best method developed so far is to use the absorption of a small dose of an Fe salt as a measure of the ability of the individual to absorb Fe. The absorption from this reference dose will thus serve as a basis of comparison for different groups of subjects. It may also serve as an indicator of the Fe status of the subjects, and thus as a basis for setting a rough border-line between subjects with normal $\mathrm{Fe}$ status and those with $\mathrm{Fe}$ deficiency. At our laboratory, using the technique described in this paper, we have considered an $\mathrm{Fe}$ absorption value of $30 \%$ from the $3 \mathrm{mg}$ reference dose to be a border-line value. This value is considered to be the lowest absorption value in the Fe-deficient section of the population. The hypothetical population with this absorption value may thus be regarded as the target group for an $\mathrm{Fe}$-fortification programme.

The absorption of $\mathrm{Fe}$ from a particular meal may be expressed as the linear regression line of the amount of $\mathrm{Fe}$ absorbed from the reference dose and the amount of Fe absorbed from the food. The three regression lines shown in Fig. 3 represent the unfortified meals and the meals fortified to $4^{\circ} \circ$ and I $13 \mathrm{mg} \mathrm{Fe}$ respectively. The values for the slopes of the regression lines obtained in this study is thus determined both by the Fe status and by the composition of the meals and the level of Fe fortification. These regression lines can then be used to estimate the expected increase in the amount of $\mathrm{Fe}$ absorbed when the amount of $\mathrm{Fe}$ absorbed from the reference dose is $30 \%$, i.e. in the border-line subjects who have the lowest level of $\mathrm{Fe}$ absorption in the Fe-deficient section of the population. When an additional $1.6 \mathrm{mg} \mathrm{Fe}$ is provided in this type of meal, the amount of Fe absorbed could be estimated to increase by $0.13 \mathrm{mg}$ in this group of subjects. When an additional $8.9 \mathrm{mg} \mathrm{Fe}$ is provided the amount of $\mathrm{Fe}$ absorbed could increase by $0.7 \mathrm{mg}$.

This study was a first attempt to develop a method for predicting the effects of $\mathrm{Fe}$ fortification. The present results are given as an example of this new method of analysing food-fortification studies.

When changing the composition of the meals the values for the slopes of the regression lines will be changed. It is therefore important to use several different meals with a composition similar to the average consumption in the population. In a recent study done at our laboratory it was shown that the way in which the food is served influences the absorption of Fe (Björn-Rasmussen, Hallberg, Magnusson, Rossander, Svanberg $\&$ Arvidsson, 1976). Therefore, attempts should be made to serve the meals in as realistic a way as possible.

The accuracy of the calculations depends mainly on the extent of the correlation 


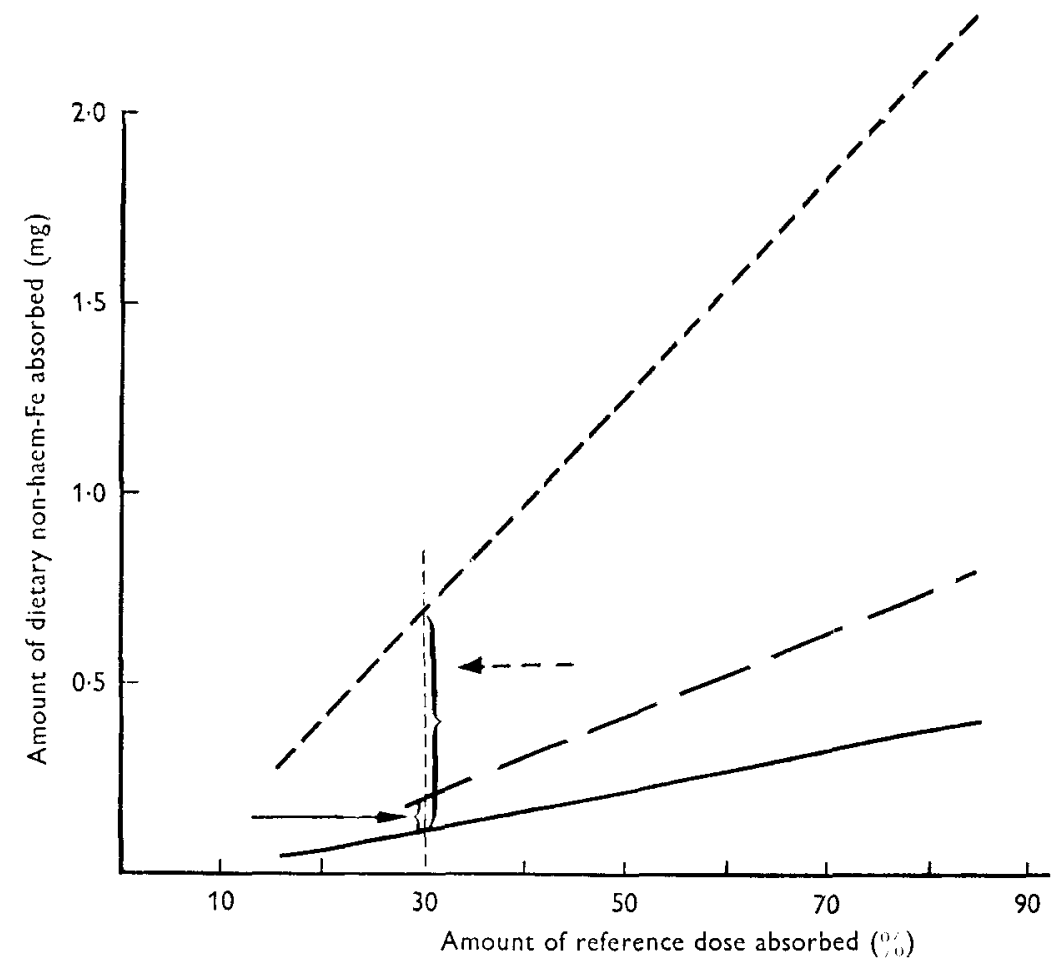

Fig. 3. Linear relationship between the absorption of non-haem-iron from a meal of 'lunch' or 'dinner' type (unfortified $(2.4 \mathrm{mg} \mathrm{Fe})(-)$ or fortified to the level of $4.0(--)$ or II'3 (-.-) $\mathrm{mg} \mathrm{Fe}$ ) and the absorption of a reference dose of $3 \mathrm{mg} \mathrm{Fe}$ as ferrous ascorbate. Fortification of the meal to $4^{\circ} \circ$ and I I.3 $\mathrm{mg}$ Fe increased the Fe absorption by $0.13(\rightarrow)$ and $0.70(-\rightarrow)$ mg respectively. Regression coefficients were: unfortified meals, $0.70(n$ 37); meals fortified to $4.0 \mathrm{mg} \mathrm{Fe}, 0.62$ ( $n$ I9); meals fortified to $11.3 \mathrm{mg} \mathrm{Fe}, 0.8 \mathrm{I}(n \mathrm{I} 8)$. For details of meals and experimental procedures, see pp. 378,379 .

between the amount of $\mathrm{Fe}$ absorbed from the meals and that absorbed from the reference doses. In a recent study from our laboratory it was shown that the extent of correlation was high when the reference doses and the meals were given on consecutive days, and was lower when the meals and the reference doses were given 2 weeks apart (Björn-Rasmussen et al. 1976), particularly for women. This may be the reason for the low correlation found in the present study, where the meals and the reference doses were given with an interval of 2 weeks. The correlation coefficient for the regression of the amount of $\mathrm{Fe}$ absorbed from the unfortified meals $v$. the amount of $\mathrm{Fe}$ absorbed from the reference doses was 0.70 for all subjects and $0.9 \mathrm{I}$ for the men only; the corresponding values for the meals fortified to $4 \mathrm{mg} \mathrm{Fe}$ were 0.62 and 0.79 , and for the meals fortified to $\mathrm{II} \cdot 3 \mathrm{mg} F e$ were $0.8 \mathrm{I}$ and 0.88 respectively.

It is well known that when increasing oral doses of $\mathrm{Fe}$ are given in the form of an $\mathrm{Fe}$ salt the total amount of $\mathrm{Fe}$ absorbed will increase, while the relative amount of $\mathrm{Fe}$ absorbed will decrease. The finding in the present study that the relative amount of $\mathrm{Fe}$ absorbed did not decrease but instead increased when the level of fortification of a composite meal was increased was therefore quite unexpected. In a previous study 
the effect of a threefold increase in the level of Fe fortification was measured in three composite meals served on $2 \mathrm{~d}$ to normal subjects. No significant decrease in the relative amount of $\mathrm{Fe}$ absorbed was found when the total amount of $\mathrm{Fe}$ in the meals was increased from 16.4 to $25.5 \mathrm{mg} / \mathrm{d}$ (Björn-Rasmussen et al. 1974). The present finding of an increase in the relative amount of $\mathrm{Fe}$ absorbed when the level of fortification of the meal served was increased thus agrees with this previous study. The probable explanation for these findings is that the properties of the non-haem-Fe pool are altered by the addition of a readily-soluble $\mathrm{Fe}$ salt. When the amount of $\mathrm{Fe}$ added to a meal is further increased the relative amount of Fe absorbed decreases, as found by Layrisse et al. (1973) who added Fe to a level of $60 \mathrm{mg} / \mathrm{meal}$.

\section{Bioavailability of reduced $\mathrm{Fe}$}

The absorption of labelled, reduced $\mathrm{Fe}$ and of other labelled Fe compounds added to foods has previously been studied in man (Steinkamp, Dubach \& Moore, 1955; Elwood, I968; Höglund \& Reizenstein, 1969). Results of such studies indicate that different $\mathrm{Fe}$ compounds differ in availability. The great variation in absorption between different subjects and the marked influence of the composition of meals on Fe absorption makes it very difficult to interpret the results and to make valid comparisons between different $\mathrm{Fe}$ compounds.

The bioavailability of an Fe compound to be used for fortification should preferably be compared with that of readily-soluble, simple Fe salt, e.g. $\mathrm{FeSO}_{4}$, given to the same subjects and in the same type of meal. Earlier studies on the bioavailability of 'fortification' Fe have mainly been carried out in animals. Unfortunately, however, it is difficult to translate the results of such studies to humans. The only direct measurement of bioavailability of 'fortification' Fe in man is that reported by Cook, Minnich, Moore, Rasmussen, Bradley \& Finch (1973) who compared the absorption of Fe from $\mathrm{FeSO}_{4}$ with that from a specially-prepared, reduced $\mathrm{Fe}$.

The present measurements of the bioavailability of reduced $\mathrm{Fe}$ are based on the concept of a non-haem-Fe pool in a meal (Hallberg \& Björn-Rasmussen, 1972). Fe added as an easily-soluble, radio-Fe-labelled salt to a fortified meal will exchange with, and uniformly label the intrinsic non-haem-Fe. The dissolved fraction of the radioFe-labelled, reduced $\mathrm{Fe}$ will similarly exchange with the other non-haem-Fe in the pool. The value for the ratio, the amount of absorption of the radio-Fe originating from the reduced $\mathrm{Fe}$ : the amount of absorption of radio-Fe from the tracer added to the food will then be a direct measure of the bioavailability of the reduced Fe under the conditions studied.

Theoretically, however, the tracer used to label the intrinsic Fe might also exchange with some of the undissolved and unavailable part of the reduced Fe. It may also be adsorbed onto the surface of the Fe particles. This would then lead to falsely low Fe absorption values and to over-estimation of the bioavailability. This was the reason for choosing two experimental models in the present studies on the bioavailability of reduced $\mathrm{Fe}$. In the first model the $\mathrm{Fe}$ in the food and the reduced $\mathrm{Fe}$ sample added to the food were labelled with two different isotopes and were given in the same meal, as described previously (see p. 379). In the second model the same amount of $\mathrm{Fe}$ in 


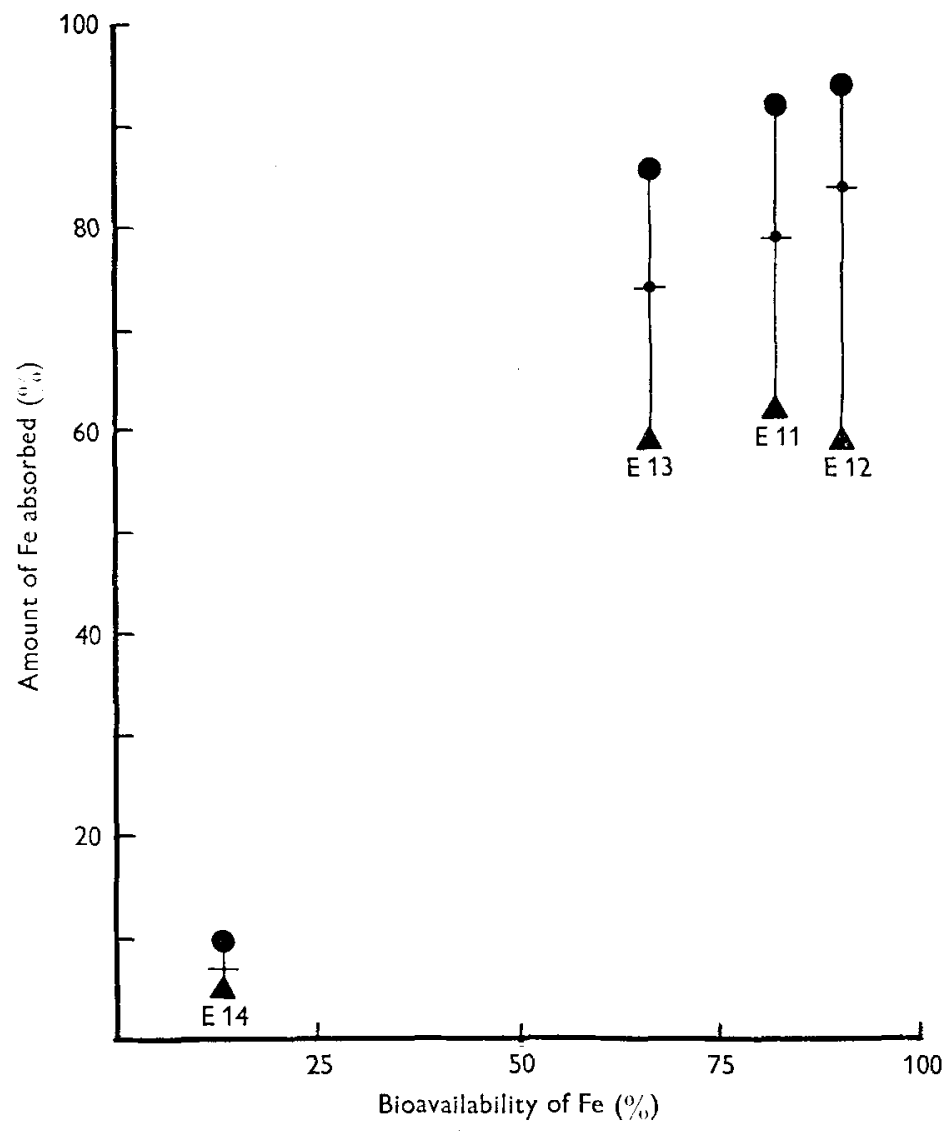

Fig. 4. The relationship between dissolution rates (amount of iron dissolved in $0.1 \mathrm{M}-$ hydrochloric acid at $\mathrm{I} O(\boldsymbol{\Delta}), 20\left(-\boldsymbol{O}_{-}\right)$and $3 \circ(-)$ min intervals after the start of agitation) and the bioavailability (\% Fe absorbed) of different variants of a sample of radio-Fe-labelled, hydrogen-reduced Fe samples $\left(E_{1}{ }_{1}-14\right)$. For details of samples, see p. 376 and for details of determination of bioavailability, see p. 379 .

the form of $\mathrm{FeSO}_{4}$ and as a reduced-Fe compound, each labelled with a different isotope, was given in wheat rolls served on different days. No difference in the mean Fe absorption ratio was found whether the two tracers were served together on the same day, as in the first model, or separately on different days, as in the second model. It can be concluded therefore that there is no obvious isotopic exchange between the extrinsic tracer and the undissolved part of the $\mathrm{H}$-reduced $\mathrm{Fe}$ compound. The simpler experimental design in which the labelled, reduced $\mathrm{Fe}$ and the extrinsic, readily-soluble tracer are given in the same wheat roll can thus be used without introducing any measurable systematic errors. Actually, the accuracy of this simpler model is greater as it is unaffected by the variation in $\mathrm{Fe}$ absorption on different days.

Reduced Fe can be manufactured in several different ways. Different samples of reduced $\mathrm{Fe}$ vary considerably with respect to physico-chemical properties such as particle size, reactive surface area and solubility. This was also true for the compounds 
used in this study (Table I). Unfortunately, it was only possible to obtain labelled samples of the $\mathrm{H}$-reduced $\mathrm{Fe}$ compound (sample $\mathrm{E}$ ) which was manufactured in Sweden. No direct information about the bioavailability of any other Fe compound could thus be obtained.

It is reasonable to assume that there is some relationship between dissolution rate and bioavailability. The present findings with the labelled compounds (samples EI I${ }_{4}$ ) support this assumption (Fig. 4). Two samples, EI $_{3}$ and EI4, were made coarser than samples EII and EI2 and sample EI4 was made less soluble than samples EI I and $E_{12}$, in order to facilitate a study on the relationship between bioavailability and solubility. Determination of the dissolution rate might therefore be used both as a screening method in the search for 'Fe-fortification' compounds with suitable bioavailability properties and to study the effect of storage.

The relationship between dissolution rate and mean particle size (Fig. 2) suggested that samples B, C and A, G respectively were almost equally soluble. However, the particle size differed markedly and, moreover, the difference in particle size between the samples C, D, Er and F was small but the solubility differed markedly. It can be concluded therefore that the particle size is a poor predictor of the solubility and of the bioavailability of an 'Fe-fortification' compound. On the other hand, a close relationship was found between the reactive surface area and the dissolution rate (Fig. 2). This finding indicates that the reactive surface area is a better predictor of the dissolution rate and of the bioavailability in man than is the particle size.

Two of the labelled, reduced-Fe compounds (samples EII and I2) were readily soluble and also had a bioavailability which was close to that of $\mathrm{FeSO}_{4}$. The unlabelled compound (sample $E_{I}$ ), prepared by the same procedure, had the same physicochemical properties. In the study by Cook et al. (I973) a specially-prepared reducedFe compound was used which also had a high bioavailability in man. However, no information was given on the chemical properties of this Fe compound.

The general conclusions that can be drawn from the present study are that there are considerable variations between different kinds of reduced $\mathrm{Fe}$, not only in particle size distribution but also in reactive surface area and dissolution rate. The present findings indicate that such variations are associated with differences in bioavailability in man. The reactive surface area of reduced $\mathrm{Fe}$ and the dissolution rate seem to be better predictors of bioavailability than the particle size.

The studies on bioavailability of reduced Fe were made possible by the close co-operation between the authors and the staff of Elektrokemiska AB, S-445 or Surte, Sweden. Thanks are due to Mrs Helle Persson and Mrs Gunilla Magnusson for skilful technical assistance. The study was supported by the Swedish Board for Technical Development. 


\section{REFERENCES}

Arvidsson, B., Sköldborn, H. \& Isaksson, B. (1972). Proc. 3rd int. Conf, med. Phys, including med. Engng 4r, 2.

Björn-Rasmussen, E. (1973a). Scand. F. Haemat. II, 391.

Björn-Rasmussen, E. (1973b). Scand. $\%$. Gastroent. 8, 645.

Björn-Rasmussen, E. (1973 C). Am. Y. clin. Nutr. 26, 131 r.

Björn-Rasmussen, E., Hallberg, L. Isaksson, B. \& Arvidsson, B. (1974). F. clin. Invest. 53, 247.

Björn-Rasmussen, E., Hallberg, L., Magnusson, B., Rossander, L., Svanberg, B. \& Arvidsson, B. (1976). Am. Y. clin. Nutr. 29, 772.

Björn-Rasmussen, E., Hallberg, L. \& Walker, R. B. (1972). Am. F. clin. Nutr. 25, 317.

Brunauer, S., Emmett, P. H. \& Teller, E. (1938). F. Am. chem. Soc. 60, 309.

Cook, J. D., Layrisse, M., Martinez-Torres, C., Walker, R., Monsen, E. \& Finch, C. A. (1972). J. clin. Invest. 5x, 805 .

Cook, J. D., Minnich, V., Moore, C. V., Rasmussen, A., Bradley, W. E. \& Finch, C. A. (1973). Am. . clin. Nutr. 26, 86r.

Eakins, J. D. \& Brown, D. A. (1966). Int. F. appl. Radiat. 17, 391.

Elwood, P. C. (1968). Rep. Publ. Hlth med. Subj., Lond. No. I 7 .

Hallberg, L. \& Björn-Rasmussen, E. (1972). Scand. Y. Haemat. 9, 193.

Herbert, V., Gottlieb, C. W., Lau, K-S., Fisher, M., Gevirtz, N. R. \& Wasserman, L. R. (1966). ¥. Lab. clin. Med. 67, 855 .

Höglund, S. \& Reizenstein, P. (1969). Blood 34, 496.

International Committee for Standardization in Hematology (1971). Br. F. Haemat. 20, 45 I.

Layrisse, M. \& Martinez-Torres, C. (1972). Am. Y. clin. Nutr. 25, 401.

Layrisse, M., Martinez-Torres, C., Cook, J. D., Walker, R. \& Finch, C. A. (1973). Blood 4r, 333.

Sköldborn, H., Arvidsson, B. \& Andersson, M. (1972). Acta radiol. Suppl. 313, 233.

Steinkamp, R., Dubach, R. \& Moore, C. V. (1955). Arch. intern. Med. 95, 181. 